\title{
Antijudería en España
}

\author{
JOSÉ JIMÉNEZ LOZANO
}

\section{I}

Creo que no hay ningún inconveniente en aceptar, pese a lo que tiene de contundente y de reductora, la afirmación de Américo Castro de que la Contrarreforma española fue, antes que cualquiera otra cosa, una "contra-judería"; por el contrario, me parece un excelente punto de partida para matizar las cosas, hasta donde nos es posible, en este asunto de la actitud hispánica ante los judíos. Y la primera matización, por inexcusable, sería, desde luego, para señalar que el juicio de Castro no podría aceptarse sino en el plano de la Contrarreforma en su aspecto sociológico y político, y de los estereotipos que produce hasta conformar todo un "Zeitgeist", un espíritu del tiempo; y, en modo alguno podría ser de recibo si se refiriese al espíritu contrarreformista, que, como ya ha quedado demostrado, forma un todo y un mismo contexto con el espíritu prerreformista, reformista, y contrarreformista, o de lo que se suele denominar, "Reforma Católica", de la que no pocos descendientes de judíos formaron parte ciertamente. Pero no cabe duda de que, en el primero de los sentidos de que he hablado, es la institución inquisitorial, paradigma y alquitara de la casta de cristianos viejos, la que la "contra judería" encarna.
Lo que le ocurre a la Inquisición española, que ha sido erigida para investigar y castigar la falsa conversión de judíos e islámicos, es que, cuando llega el luteranismo, exactamente como le ocurre en el caso de todo el abigarrado paisaje de la religiosidad y las espiritualidades interiores, o las posiciones teológicas de crítica frente a la Cristiandad establecida -desde los místicos a los alumbrado, dejados, y recogidos, hasta los erasmistas- es que comprueba que el grueso de los individuos componentes de esos grupos y sus "próximos" son "ex illis", esto es, descienden de conversos; $y$, entonces, esta condición se convierte, por sí sola, ineluctablemente, en signo y como fuente de toda herejía; y, este silogismo "a contrario" diremos que es el que hace, pongamos por caso para ofrecer un ejemplo entitativo y verdaderamente paradigmático, el inquisidor Diego González, de la Casa de Valladolid, hechura por cierto del Gran Inquisidor Valdés, cuando tiene decidida la detención de fray Luis y de los otros hebraístas salmantinos; y la razona ante la Suprema; construye lo que podríamos llamar el silogismo perfecto, o al menos indiscutible e indiscutido para los señores de la Casa y la aplastante mayoría de la población hispánica, y dice: "Por ser Grajal y Fray Luis notorios conversos, pienso que no deben querer más que oscurecer nuestra fee catholica, e bolberse a su ley". 
La dialéctica de los denunciadores y de los calificadores del tribunal era un poco más erudita, pero igual de simple, clara, y contundente. Estos hebraístas, decían, sostienen que la traducción griega de la Biblia, llamada de Los Setenta, tiene errores, y que la Vulgata latina puede y debe mejorarse, mientras que estiman necesario acudir a la Biblia Hebrea, pero esta Biblia está intencionadamente corrompida por los judíos masoretas, cuando la vocalizaron para que las palabras no pudieran ser leídas de modo que pudiera mostrarse la mesianidad de Cristo; y, si además esos hebraistas son "ex illis", que se habían aupado por todas partes, la conclusión era la misma: los hebraistas querían judaizar la fe cristiana, completando esta empresa al arremeter contra la escolástica y la patrística, unas teologías que estarían hechas en la ignorancia del texto verdadero de la Biblia. Y León de Castro, uno de los catedráticos acusadores de fray Luis, tenía tan claro como el señor inquisidor Diego González que cosa de judíos era; como protervia judía serían el luteranismo y todo lo demás. Y quizás los señores inquisidores no se enteraron nunca del antisemitismo de doctor Lutero, pero, si se enteraron, se callaron como muertos, porque, desde luego, ello no aportaba peso precisamente a su empresa de lucha antiprotestante, equiparada ya a lucha contra la "judería", o "anti-judería", que, como se ve claramente, en principio no tiene nada que ver con antisemitismo ni racismo en sentido estricto; y no queda memoria de que la Inquisición persiguiese a nadie por su etnia unida a la creencia práctica judaicas, y podríamos añadir que, hasta que España no se "europeizó", tampoco se le había ocurrido a nadie en esa España, de la que la Inquisición era la alquitaradora de la pureza de la fe de su pueblo, que un judío, pongamos por caso, de Segovia o de Gerona, no fuera español, ni que había que expulsarle del país si no se con- vertía. Pero esto ocurrió, y entonces la Inquisición se convirtió, de ser una empresa de anti-judería intelectual o teológica, en el gran instrumento de mera pureza racial, en la que la cristiandad quedaba resumida y a la que resultaba equiparada. Ya no habrá más teologías de por medio que valgan, y, desde luego, nada significa la propia tradición religiosa, y los maestros en esta fe castiza ya no serán los obispos, sino la Inquisición misma, que expresa el espíritu del pueblo, "Volksgeist", y es abiertamente un Departamento de la Administracíón del Estado, uno de los Reales y Supremos Consejos.

Cuando en 1609, se decide la expulsión de los moriscos, y los obispos tratan de defender a sus propios fieles moriscos saliendo garantes de su cristiandad, y hasta haciéndose eco de su piedad ejemplar, el conde de Salazar, encargado por el rey de conducir técnicamente esa expulsión, muestra a esos obispos los términos exactos en que ésta se va a realizar a tenor de criterios idénticos a los manifestados por el Licenciado Diego González en el proceso de los hebraístas: la medida de cristiandad será que hayan comido tocino y bebido vino, y no hayan hablado en algarabía, esto es, en árabe. No habrá otra teología. Así de simples, y así de complicadas al mismo tiempo son las cosas, porque delicada, y dramática, y compleja, es ciertamente la historia hasta que da en esas claridades y certezas del señor conde, los señores inquisidores, y el buen pueblo de casta de labradores, que nada tiene que ver con las letras, y cuyos antepasados son de una tan limpia sangre como quizás no tendrá el arzobispo de Toledo mismo, que podría cojear, si se busca, de abuelos y trasabuelos que iban a la "sinoga".

\section{II}

Pero, antes de ser las cosas como vengo diciendo, fueron de muy otra manera, que, 
por lo demás, tampoco hay que pintar con los colores de una Arcadia. La historia nunca ha sido idílica, sencillamente a veces ha estado más cerca que otras de ser más racional, humana y vividera. El hombre siempre ha sido el hombre, y sus instintivas pulsiones de extrañeza y rechazo del "otro" que es diferente están en su naturaleza, y las comparte con las gallinas mismas de su corral; el puro discurso racional puede hacer bien poco por aplacar siquiera esas pulsiones. Pero también es un hecho en la historia que, a veces, una construcción social sin costricciones, unos intereses sociales, políticos y económicos bien trabados en la comunidad, a la vez que unos vínculos de intereses humanos también comunes muy profundos, y el surco, en fin, que en las mentalidades sociales como en los individuos labran con el tiempo religiones y éticas en las que los hombres importan, y hasta el mismo bienestar y la alegría de vivir, compartidos, han soterrado esos instintos, creando incluso como segundas naturalezas más o menos recias. Y, desde luego, un poco o bastante de todo esto hay en la España medieval, en la que se da, de modo para nosotros llamativo, una convivencia vividera de tres leyes o creencias, tres castas, y tres antropologías o culturas.

La sociedad de las Españas de ese tiempo es europea, naturalmente. Tiene una historia vertical, común con Europa, de romanización y aporte cultural bárbaro cristianizado, y con Europa comparte la recepción del Derecho Romano y bizantino, y las instituciones que se alumbran en ese medioevo: la catedral, la "universitas", el "municipium", los monasterios, y la estructura social de estamentos: el guerrero, el clérigo, el campesino, es igualmente similar; pero aquí hay judíos, y no del mismo modo que como están en el resto de Europa, y hay islámicos de los que esa Europa sólo guarda el imaginario de las invasiones y las cruzadas, pero que aquí son vecinos.
Aquí no hay "ghettos" donde se encierra a los judíos, sino juderías donde viven a veces por razones de similar oficio, o instaladas al amparo del palacio del rey o de la Iglesia en previsión de los "pogroms", que también a España llegan desde luego. Es decir, juderías y morerías son simples hábitats de gentes afines, como hay calles de Tedescos, Francos, Gascones, Milaneses o Flamencos. No son encerramientos. Así que, cuando doña Catalina de Láncaster se casa con Enrique III el Doliente, y va a Segovia, no puede menos de extrañarse de que los judíos anden por las calles principales tan "desembargadamente", es decir, ocupando mucha acera incluso, toda la que necesitan, como no dejan de acompañar sus nombres con un "don" o un "doña”. Sólo más tarde, cuando los demagogos políticos y religiosos enseñen a verlo, se verá ahí orgullo, y señales de aupamiento.

Pero es que el desconcierto de los cortesanos que acompañan a Carlos I, cuando llega por primera vez a la península, alcanza su colmo, recién desembarcados al encontrarse con los nobles castellanos que han salido a recibir al monarca, y ven a uno de ellos vestido "como un Rey Mago", según escribirán luego, porque ésa era la idea más aproximada que aquellos flamencos podían hacerse de "un moro". Pero es que aquí, se vestía a la "usanza mora", como a la misma usanza había baños, y señores y plebeyos en alcatifas se recostaban. Aquí, en España, ciertamente, el ventanal gótico de una iglesia podía dar a un corralillo islámico, y un mirador donde un judío meldaba podía dar a un jardín de monjas cistercienses. Es decir, esta España, que era Europa, era también Oriente; y esto quiere decir que el paisaje humano y social no es tan unidimensional como en la Europa cristiana del tiempo, sino que también muestra los coloridos, digamos que de las sociedades "bizantinas" o de entrecruce de etnias, religiones y cul- 
turas, de las sociedades de una frontera que pasa por cada casa en una misma ciudad o aldea, $y$, a veces, por cada individuo o grupo de ellos dentro de la misma familia; y podríamos recordar el caso del cura de Tajahuerce, en Soria, de finales del XV, cuya madre y hermana son judías no convertidas. Cuando con él nos encontramos en los papeles, resulta que confiesa hallarse en una situación de perplejidad respecto a cuál de "las tres leyes" sería "la verdadera", y que ha durado años, sin llevarle a determinación alguna, hasta esa fecha en que ya no podrá seguir de ese modo por pura presión religioso-política inquisitorial, que exige la homologación. Pero esto será a fines de ese siglo como digo.

En tanto que España es Europa, también hubo aquí "pogroms", como se señaló más arriba, y no menos atroces que en otras partes; y, cuando los Reyes Católicos recién casados van a Segovia, todavía hay paredes de las casas que están manchadas de sangre. Y todos esos "pogroms" han sido predicados y azuzados, desde el Arcediano de Écija a san Vicente Ferrer, con las categorías de la teología románica europea antisemita, que, por cierto, también había aplicado esos sus puntos de vista procesalmente a la cuestión de la apostasía de los judíos conversos, que volvían a su antigua ley, y ahí han quedado escritos, por ejemplo, en el "Manual de Inquisidores" de Eymerich; pero esta teología europea no era la única que había en las Españas, ni tampoco la predominante y universalmente aceptada. Por la simple y obvia razón de que aquí los judeo-conversos también eran clérigos, que habían leído su Nuevo Testamento, donde Pablo les aseguraba que ya no había ni judío ni griego, y entre el pueblo quedaba además el antiquísimo saber y sabor de los tiempos de la evangelización del país que no tenía ni rastro de otra preocupación herética que la de las divergencias del Credo, y se acordaba perfectamente con la teología uni- versalista y misericordiosa que los conversos habían levantado para anclarse en su nueva fe. Y éste es un aspecto tan central en la historia del sentimiento religioso hispánico que, sin hacer cuenta de él, no podrá entenderse luego ni "la teología" de los quemadores de templos, destructores de imágenes, y asesinos de clérigos, frailes y monjas, de extracción popular, y que en modo alguno son solamente puras víctimas de ideologías seculares y ateístas, con odio religioso.

Es del máximo interés, a este efecto, escuchar las más tempranas declaraciones inquisitoriales, en las que los acusados, gentes del pueblo sin instrucción específica y desde luego sin asomo de grandes estudios teológicos -aunque entre esos acusados tampoco faltan clérigos, y algunos ciertamente doctos como más tarde ocurrirá, pero en general pobres curas de aldea, que son quienes nos importan en este caso, porque ellos nos ofrecen la pista de lo que predican y las gentes del común comparten- responden a los inquisidores con las cuatro cosas que saben y con la mayor firmeza, afirmando la universalidad de la fe por encima de toda condición o circunstancia individual, con la enfatización de que una sinagoga es templo de oración al igual que una iglesia, como Alfonso X, decía, por lo además, en sus Partidas; recordando a sus señorías los inquisidores la seriedad de la presencia eucarística frente a lo insignificante de unas reliquias de santo más o menos verdaderas, y, desde luego, negando todo poder a la Inquisición misma para separar a nadie de la cristiandad, ni para hacerse dueña de sus dineros, $\mathrm{y}$, a mayor abundamiento, criticando el imperialismo papal del tiempo. Es pura ortodoxia; pero no era la ortodoxia europea, y muy en especial por lo que afectaba al fenómeno de la conversatio cum haereticis, que aquí era cada día y cada noche, porque el hereje vivía pared con pared, o, como mucho, unos metros de la calle 
más abajo, y con él se vivía y se convivía, se le invitaba o se era invitado por él, y no sólo se hablaba de "la ley" de cada cual, sino que los unos y los otros iban al culto que cada cual tenía, y tenemos testimonios de horas enteras pasadas en las sinagogas, de rezos de cristianos en ellas cuando encuentran ya cerrada la iglesia, al dejar el trabajo, y de judíos encantados de que en las iglesias se hable de Moisés, Isaías, Ezequiel, José, Jacob, y los otros patriarcas y profetas del Antiguo Testamento. Una y otra vez, los concilios provinciales tratan de atajar los peligros de irenismo que de ahí pueden derivarse, pero nada logran, e incluso en ceremonias publicas de la Iglesia rabinos y alfaquíes tienen un lugar muy señalado, de obsequiosidad desde luego a "la nueva ley", pero sin que eso suponga que tengan que abandonar la suya.

En las cuatro inscripciones funerarias del túmulo de Fernando III, en Sevilla, se muestra perfectamente esa dicotomía de teologías en las Españas, y por dónde va la europea, que naturalmente es la de "los ilustrados", los que latín saben. En dos de los epitafios, escritos en hebreo y árabe, se dice que el rey allí enterrado "quebrantó y destruyó a todos sus enemigos"; en el epitafio escrito en romance castellano se dice lo mismo realmente: "rompió e destruyó todos sus enemigos"; pero en la latina está escrito: "contrivit et exterminavit penitus hostium suorum proterviam", y Américo Castro también, que es quien con razón se muestra extrañado de esta diferencia, comenta, sin embargo, simplemente que "protervia" equivale a "desvergüenza" o "impudor", y añade: "o sea de los musulmanes que ocupaban Córdoba y Sevilla”, lo que entiende como matiz de intolerancia explícito sólo para los que entienden el latín. Pero me parece que aquí hay algo mucho más significativo. Porque, por lo pronto, el uso de los verbos. contrivit y exterminavit explicita la violencia más extrema, y la palabra protervia pertenece al vocabulario teológico y clerical que designa la maldad con aquel sentido aristotélico de que las disposiciones morales están condicionadas por la complexión y la cuna, y equivale, quizás con mayor fuerza aún, al de pravitas o maldad específica de la herejía contra la que hasta en la enunciación misma de la institución inquisitorial se alzará ésta, Officium Sanctae Inquisitionis adversus haereticam pravitatem. Y entonces se entiende perfectamente el exterminavit que equivaldrá a la extirpavit o extirpatio del lenguaje inquisitorial más adelante. Y ésta es la violencia que se oculta a quienes no saben latín entre los cristianos, y a judíos e islámicos; ésta es la violencia como teología y sentimiento de quienes redactaron esos epitafios, la de toda una clase "ilustrada" como decía; aunque hay que añadir, desde luego, que todos "los ilustrados" que sabían latín no estarían de acuerdo, porque desposaban más bien la singularidad teológica de las Españas, o simplemente se atenían a la realidad de los hechos: aquella situación plural de sus gentes. Y no hay más que pensar en que, si el propio hijo de Fernando III, Alfonso X, el Sabio, recepciona en sus "Partidas" el Derecho Romano, también es quien señala, como se apuntó más arriba, que una sinagoga es una casa de oración lo mismo que un templo cristiano, y desde luego se siente rey de sus judíos y sus moros al igual que sus antecesores; mientras que su sobrino el Infante don Juan Manuel explicará muy bien que la guerra que hay entre moros y cristianos no es "nin por ley nin por secta", sino porque los moros se han apropiado las tierras de los cristianos, de otro modo no la habría. Ni asomo de invocación de la protervia de nadie, y "a fortiori", como con los judíos no hay cuestión de defensa de intereses, no hay ni mención de ellos lógicamente, y la educación de los hijos del propio don Juan Manuel, como la de los hijos de todos los grandes castellanos, a 
los judíos se encomendaba, cuando no la administración misma de su casa según ocurría también en este caso de don Juan Manuel. Y será preciso recordar cómo para hacer aceptar el "nuevo curso europeo de las cosas", que vendría más adelante, hubo que echar sobre la cristiandad española toneladas de viejas leyendas europeas sobre profanaciones de hostias consagradas y muertes de niños cristianos a manos de judíos, o pozos también envenenados por ellos, a más de una teología antisemita y de demagogia social, combinadas con el terror, y con la mostración de intereses económicos y de aupamiento social, que los judíos vendrían usurpando. Es decir, la ya manida preparación de un "pogrom", y el aplastamiento del profundo sentimiento cristiano de misericordia.

De manera que, en tanto que España es un país Oriental, "bizantino", o de frontera, puede decirse provocadoramente que la Inquisición será el gran instrumento de su europeización, en el sentido, desde luego, de que es un instrumento de homologación de ideas y creencias; aunque enseguida dará lugar a una singularidad específica: la equiparación total y absoluta de fe cristiana y condición racial, de cristiandad y españolidad, y no tardando mucho "lo europeo" también será asimilado a lo judaico en el enloquecido proceso de simplificación y limpieza al que la institución se entrega. La triunfante teología europea de homologación intelectual y religiosa se hace teología castiza. Y, como se dijo, ya no habrá otra; por lo menos sin amenazas y riesgos terribles para ella.

\section{III}

Todo ocurrió así, y no hubiera podido ocurrir de otra manera por causa del asunto de los conversos del judaísmo al cristianismo, pero más exactamente aún, en razón del concepto estricto de conversión como medida y peso de la conversión única verdadera y admisible.

La fe judaica -y otro tanto podríamos decir de la islámica, pero ahora es asunto dejado de lado- que empapa todo el vivir individual y social, no sólo construye un modo de ser hombre y de estar instalado en el mundo, es decir, una singularidad cultural, sino que también, a través de una serie de preceptos de orden dietético, sexual, o que afectan al vestido, a la representación plástica, a la sucesión del tiempo, crea hábitos y comportamientos o gustos, como el de la lectura y la discusión o cavilación sobre un texto o una realidad cualquiera, o el tan mentado del rechazo de la cocina de sangre, y desde luego de la carne y grasa del cerdo; y generaciones enteras han sido así modeladas psicológicamente y en cada manifestación antropológica por todo eso. A lo cual había que añadir, además, otros muchos comportamientos que el imaginario cristiano anti-judío tenía también como señal de ser de ellos, y que llegó a alambicarse hasta el mayor de los retorcimientos. Palabras como "vino" a propósito del vino, que pronunciadas por sospechoso quedaban referidas a la negación de que "ya vino" el mesías, el sentir frío después de comer, o un cierto modo de sonreírse, o ciertas fórmulas de respeto como el mostrado por los niños besando la mano a las personas mayores antes de irse a la cama, vivir de ciertos oficios o profesiones, y desde luego mostrar actitudes para el comercio y el hacer dineros, y un gran etcétera más alambicado aún, que nutre de chistes malintencionados las conversaciones de la época, y de después. Y hay que subrayar aparte que uno de esos signos judaicos es también, y muy singularmente, la piedad o misericordia.

En 1602, por ejemplo, un consultor del Santo Oficio, el Doctor Piçario de los Palacios, al calificar "De los nombres de Cristo", de fray Luis de León, nos muestra que 
no tiene noticia biográfica alguna del autor, ni siquiera de lo que en la Casa pasó con él, pero informa, desde luego, que no puede menos de ser ex illis, porque critica las prohibiciones de los terribles Estatutos de limpieza de mediados del XVI, o sea cincuenta años atrás, de que los descendientes de judíos puedan entrar en las órdenes religiosas, y desempeñar oficios en la Iglesia y el Estado, y se enfrenta a la dureza de los castigos a herejes. Y esto es tener bien claras las cosas y olérselas desde lejos, porque tanto la discriminación hacia la mala casta como la dureza con ellos y otros herejes a ellos asimilados, era señal de casta limpía. ¿Hasta banalizar la quema en la hoguera, banalizar el mal, que diría Hannah Arendt, y tornarlo burocrático?. Ciertamente. Góngora mismo hace en verso crónica ligera, en un momento dado, y habla como si de cosa obvia y banal se tratara de que fueron quemadas "cincuenta mujercillas de la raza"; aunque en este caso, Góngora bien puede decir eso, porque eso era lo correcto, y ortodoxo, y él tenía sus razones para exhibir ortodoxia y limpieza de sangre, porque venía ex illis precisamente. Pero ese verso nos otorga aún más enfáticamente la medida de que la misericordia y la compasión son signo de mala casta, y la dureza expresión misma de la ortodoxia que lucha hasta su destrucción física contra "la protervia judaica", según la fórmula inquisitorial estereotipada. Y Julio Caro Baroja ha señalado agudísimamente que toda $\mathrm{y}$ sola la literatura de conversos -quizás con una sola excepción, diría yo, la de Alejo Venegas, autor de Agonía y tránsito de la muerte - es sensible a la piedad y la misericordia, la compasión por la desgracia ajena; mientras en la literatura de cristianos viejos, remacharé también por mi cuenta, el sufrimiento de los más pequeños es mero material estético, cuando no una inmisericorde burla de él y los sufrientes.

Así las cosas, la conversión verdadera no es preciso que consista esencialmente en el abandono del mosaísmo o religión judía, y el abrazarse de todo corazón a la cristiana, pero sí debe consistir en el abandono total de todas las manifestaciones antropológicas o imaginarias del ser judío; aunque, aun así, estará siempre pendiente sobre los conversos más sinceros la antigua mancha de descender ex illis, que es algo así como ontológica e irrenunciable: "ovejas roñosas" y "generaciones de afrenta que nunca se acaba", como dirá muy exactamente fray Luis de León, que lo sufrió en su carne y en la de los suyos. Nunca podrían ser estos sinceros conversos ni cristianos pacíficos y a parte entera, ni, por lo tanto, españoles del todo. Es decir, no se trata solamente de que el pobre converso tuviera que comer con "duelos y quebrantos" de su corazón, menudillos y sangre o huevos con torreznos -que por eso se llamaban así, y en la primera página de "El Quijote" están-, sino que el mismo vivir entre cristianos "limpios" y "de buena casta", y hasta aspectos enteros de la vida religiosa cristiana historizada ya como anti-judaismo, incluida la dureza de alma y desprecio de la misericordia y el perdón, resultaban para esos cristianos, que vivía una religión interiorizada, y de riquísima vida interior con frecuencia, un duelo y un quebranto del corazón y del ánima. Y hasta Juan de la Cruz, que ya podemos mostrar que fue también uno más ex illis, y que en sus escritos no tiene sino escasísimas referencias a la socialidad en que vive, se alza contra romerías y procesiones, y el indecente aparato de orgullo de las sepulturas tan ligado al orgullo de la casta, y, también como en aquéllas, a la idolización de la figura, y en este caso figura de riqueza y poder soberbio e inmisericorde de hombre que se ha levantado sobre los demás en vida, y quiere levantarse en la muerte.

Se era, pues, judío para siempre, si se venía de ellos; y todo el mal que podía venirle, si tenía que rendir cuentas ante 
los señores inquisidores, de su judaísmo, de su condición de descender de judíos le vendría; o, en cualquier caso, sería algo que pesaría con peso decisivo. Toda "herejía" o "heterodoxia", inconformismo extrañeza y "otreidad", se suponía, por principio, que de judíos venían, y cosa de judíos eran; y este simplicísimo estereotipo inquisitorial, y super-simplicísima teología del barroco, se convertirán enseguida en social y mental estereotipo con el que se juzgará toda novedad que advenga de fuera a la España de limpia cristiandad, desde ese tiempo para en adelante, hasta el socialismo, el comunismo, o una simple moda femenina que contradecía el imaginario ejemplar de la dama barroca, o la existencia del hombre de libros y cavilaciones, que, como decía Humillos, el candidato a alcalde de Daganzo, cuando fue examinado para ello y negó saber leer con mucho orgullo, es cosa que "lleva a los hombres al brasero/ y a las mujeres a la casa llana", y, por eso Teresa de Avila tiene tanto interés en mostrarse como ayuna de letras y lectura,

Todo un pueblo, entonces, adquiere más y más un estereotipo y una sensibilidad antijudaicas, con la práxis demagógica inquisitorial, apuntalada una y otra vez, con los grandes espectáculos de los autos y quemas, y el énfasis y glorificación de la casta limpia del linaje de labradores -y mejor si no tienen letras-, que es absolutamente insospechable, como lo es la condición de vasco, que, por su incontaminación de judíos e islámicos, se alza a espejo mismo de la españolidad-cristiandad. Y no podríamos decir que se trata de antisemitismo en su sentido estricto, es antijudaismo o antijudería, que es, desde luego, sustancia o realidad biológica, que mancha indeleblemente, y podría pasar por antisemitismo; pero se trata, a la vez, de la consideración de lo judaico como una realidad metafísica o teológica, que está a la base de toda protervia herética y tiñe de judío -y torna judío- a todo lo que no es la "ortodoxia" de un cierto catolicismo historizado y una cierta antropología decidida como la única española, y a quien no da esta medida ni este peso. Estamos aquí en zonas de metafísica y teología como digo, que, por cierto, como ha señalado Emile Fackenheim, Hitler tuvo muy en cuenta al graduar la función específica de cada campo de concentración y muerte: la extinción o limpieza debería ser en primer lugar y de modo absoluto para aquellos cuyos abuelos hubieran ido a la sinagoga. Esto es, tuvieran el "veneno teológico", por decirlo así.

La "desjudaización" del cristianismo a que dio lugar esta antijudería equivale ciertamente a una, digamos "segunda catolización o recatolización de España", de consecuencias desastrosas para la cristiandad del país, hasta separarla de las raíces bíblicas de la fe, pero no menores para la cultura, incluso por la tala de estas mismas raíces, en razón de la banalización de la mirada que supone esta ausencia para el pensar y la literatura y el arte, cuyo único camino daría al puro formalismo, de uno u otro modo, y para en adelante, con escasísimas excepciones, que, como en el caso de las golondrinas cuando se trata de una sola, no hacen primavera ni verano. Y no sacaríamos otras conclusiones de la paremiología, o de las investigaciones sobre el imaginario popular en relación con los judíos, aunque, en este caso, más arrimadas que a otra cosa, a las propagandas políticas y a los estereotipos sociales modernos, al antisemitismo vulgar, que siempre es de fabricación circunstancial.

Lo que me pregunto es si el soterramiento de la específica tradición cristiana, que ya sobrevivió tan escasamente a la empresa desjudaizadora de la Inquisición, y de la literatura y las artes, y la misma tradición popular, también desjudaizada y banalizada en la aceptación de la "doxa" de cada momento, estaría ahí todavía como 
empalizada infranqueable frente a una nueva empresa de Holocausto. Porque también me pregunto en qué medida la España entera, "bizantina" y de frontera existe por lo menos en el territorio de los espíritus y de las mentes y sensibilidades; y cómo podría pensar pensamiento verdadero, si el camino a Jerusalén -en el que las más altas y profundas voces españolas expresaron la gloria y lo trágico del vivir humano- estuviese cerrado y concluido. Pero no sé responderme, y me da miedo. 